\title{
Style versus Service? An Analysis of User Perceptions of Transit Stops and Stations
}

\author{
Hiroyuki Iseki, University of New Orleans \\ Brian D. Taylor, University of California at Los Angeles
}

\begin{abstract}
Transit travelers expend a great deal of time and energy on out-of-vehicle walking and waiting, which significantly affects their perceived burdens of travel. Accordingly, this article is concerned with ways to reduce the perceived burdens of out-of-vehicle time spent walking, waiting, and transferring to improve users' experience at transit stops and stations. We surveyed 749 transit users at 12 transit stops and stations around metropolitan Los Angeles and found that the most important determinant of user satisfaction with a transit stop or station has little to do with the physical characteristics of the facility; instead, frequent, reliable service in an environment of personal safety matters most to riders. In other words, most transit users would prefer short, predictable waits for buses and trains in a safe, if simple or even dreary, environment over long waits for late-running vehicles in even the most elaborate and attractive transit station, especially if they fear for their safety.
\end{abstract}

\section{Introduction}

Travel by public transit involves much more than moving about on buses and trains. A typical door-to-door trip entails walking from one's origin to a bus stop or train station, waiting for the vehicle to arrive, boarding the vehicle, traveling in the vehicle, alighting from the vehicle, and then walking to one's final destination. 
In many cases, the trip involves transfers; travelers alight from one transit vehicle, move to a new stop or platform, wait for another transit vehicle, and board that vehicle. Transit travelers expend a great deal of time and energy on this out-ofvehicle walking and waiting, which plays greatly into their perceived burden of transit travel. Despite the importance of out-of-vehicle transit travel, the in-vehicle travel experience has tended to garner the lion's share of attention from transit managers and researchers.

As cities have grown more dispersed and auto-oriented, the out-of-vehicle time share of transit trips has increased. In an effort to accommodate increasingly dispersed patterns of trip-making, many transit systems in U.S. metropolitan areas now require transit users to make frequent transfers among lines, modes, and operators. In metropolitan areas with large transit systems, transit stops and stations are integral parts of the transit network, playing an important role in connecting multiple transportation modes and systems. The effectiveness of these connections governs waiting and walking times at transit stops and stations, and, in turn, travelers' choices regarding whether or not to take a particular transit trip. Given the effect of travel time on travel choices, good connectivity at transit stops and stations is critical to overall transportation network effectiveness.

What are the best ways to reduce these out-of-vehicle travel burdens and improve transit users' experience at stops, stations, and transfer facilities? Are some approaches to improving the interconnectivity among transit lines, modes, and systems more cost-effective than others? Can out-of-vehicle travel improvements be made in a stand-alone fashion, or are they more effectively implemented in concert with other complementary actions? To address these questions, we devised a framework to relate transit stop and station attributes to travelers' outof-vehicle burdens based on travel behavior research. Guided by this framework, we developed a methodology, which consists of Importance-Satisfaction analyses and ordered logistic regression models, to examine transit users' perceptions of services and the built environment at stops and stations. We applied this methodology to a survey of 749 transit users at stops and stations around metropolitan Los Angeles and identified the priorities that users place on means to improve their travel experience.

In sum, we found that transit users tend to care more about personal safety and frequent, reliable service than the physical conditions of transit stops and stations. In other words, given a choice between benches, shelters, and off-street stations, 
or safe, frequent service, our findings suggest that most passengers will opt for the latter.

\section{Previous Research and Conceptual Framework}

The importance of waiting, walking, and transfer times to public transit riders has long been recognized in travel behavior research (Committee on Intermodal Transfer Facilities 1974). The literature on travel time valuation has clearly documented differences between in-vehicle travel time and out-of-vehicle travel time (Iseki and Taylor 2009). ${ }^{1}$ In general, travelers perceive out-of-vehicle time (i.e., waiting, walking, and transfers) as more onerous than in-vehicle time. In his review and meta-analysis of British studies of transit travel times and service quality conducted between 1980 to 1996, Wardman (2001) reports that the average values of walking time, waiting time, and combined walking and waiting time relative to in-vehicle travel time were $1.66,1.47$, and 1.46 , respectively. A few other studies, such as Wardman et al. (2001), Kim (1998), and the U.S. Environmental Protection Agency (2000), report the value of wait time and walk time relative to in-vehicle time ranges from 1.2 to 2.72 , which varies by transit mode, trip purpose, and population size of the urban area, among other factors. Several modeling studies in the U.S. found slightly higher valuations of walking time, ranging from 2 to 4.5 times of in-vehicle time (Barton-Ashman Associates 1993; Parsons Brinckerhoff Quade and Douglas Inc. 1993, 1998, 1999).

Transit users' relative valuation of out-of-vehicle time depends on a wide array of external factors, such as quality of signage and information at transit facilities, vehicle arrival time uncertainty, ${ }^{2}$ comfort, security and safety (which are, at least in part, influenced by service frequency), weather, and crime frequency (Moreau 1992; Hess, Brown, and Shoup 2005; MVA Consultancy 1987; Bruzelius 1979; Webster and Bly 1980; Reed 1995; Ryan 1996; Wardman 2001). Out-of-vehicle travel time valuation also has been found to be influenced by transit user characteristics, such as users' familiarity with the city, transit system, given line, and given stop, as well as the physical condition of the traveler, whether the traveler is late for work or an appointment, and whether the traveler can otherwise use the waiting time productively (Bronzaft, Dobrow, and O'Hanlon 1976; Reynolds and Hixson 1992; Woyciechowicz and Shliselberg 2005; Lacy and Bonsall 2001; Dziekan, Schlag, and Jünger 2004; Dziekan and Vermeulen 2006; Dziekan and Kottenhoff 2007; Dziekan 2008; Balcombe et al. 2004). 
Because of the demonstrated importance of waiting, walking, and transferring (out-of-vehicle) times vis-à-vis in-vehicle travel times in the minds of travelers, improving travelers' out-of-vehicle (walk, wait, and transfer) transit experiences is important to making public transit more attractive to users. However, the research on how these observed out-of-vehicle travel burdens relate to the specific configurations of transit services, stops, and stations has received surprisingly little attention. And while many previous studies have investigated the physical attributes of transit stops and stations, this work has, in general, ignored much of the travel behavior research reviewed here and has lacked any conceptual logic linking stop/station improvements to increased ridership.

Why has there been so little careful research on the waiting, walking, and transferring experience of travelers? First, as noted above, both practitioners and researchers have tended to pay more attention to the quantity and quality of in-vehicle travel, probably because transit managers have more control over what happens on buses and trains than at stops and stations, which often are controlled by other entities. Second, because transfer facilities vary in size, modes served, location, and amenities, it is a challenge to comprehensively analyze transfer facilities using uniform criteria (ITE Technical Council Committee 5C-1A 1992). Third, most previous studies of transit stops and stations typically have compiled laundry lists of positive and negative attributes, but have largely failed to consider their relative importance or whether they influence ridership differently alone or in concert with other factors (Rabinowitz et al. 1989; Fruin 1985; Kittelson \& Associates 2003; Vuchic and Kikuchi 1974; Evans 2004). Most of these previous studies have been conducted from what could be best described as a design perspective, suggesting rather obvious improvements (providing more seats and shelters, improving lighting, keeping facilities clean, etc.), although research has clearly shown that the factors influencing valuation of out-of-vehicle time are not limited to certain built environment and amenities of bus stops and rail stations. Few studies, however, have measured the effects of various stop attributes on people's travel behavior. This lack of causal clarity makes it difficult for transit planners and managers to determine how to lessen the burdens of waiting, walking, and transferring at transit stops cost-effectively (Liu, Pendyala, and Polzin 1997). As a result, we know little about which attributes of transfer facilities are most important, under which circumstances, and in which combinations.

To address the shortcomings in much of the previous research on transit stops and stations, we drew on the transfer penalty work of Liu, Pendyala, and Polzin 
(1997), Wardman (2001), and Guo and Wilson (2004) to develop a wait/walk/ transfer impedance framework to systematically evaluate the attributes of the out-of-vehicle transit travel experience (Iseki and Taylor 2009). The concept of transfer penalty represents generalized costs-including monetary costs, time, labor, discomfort, inconvenience, etc.-involved in transferring from one vehicle to another of the same mode (e.g., bus to bus) or a different mode (e.g., bus to train, walking to bus, etc.), and is well-established theory in the travel behavior literature (Rabinowitz et al. 1989; Fruin 1985; Kittelson \& Associates 2003; Vuchic and Kikuchi 1974; Evans 2004; Iseki and Taylor 2009). While we intend, in a subsequent phase of this research, to relate reported user perceptions to both the physical characteristics and service frequencies at stops or stations, in this article we focus on the relative importance that users place on various aspects of their wait/walk/transfer experience at particular transit stops and stations, and their levels of satisfaction with each of these aspects.

\section{Research Method}

Drawing on the literature and our conceptual framework, we designed a survey of 46 self-administered questions to collect data from passengers on their perceptions of each of five categories of transit stop and station attributes: 1) access, 2) connection and reliability, 3) information, 4) amenities, and 5) security and safety (Iseki and Taylor 2009). Specifically, we asked transit passengers (in both English and Spanish) to assess the level of importance of multiple service features and their level of satisfaction at the stop or station where the survey was being administered under the current conditions on a four-point scale from "very important" to "not important" and "strongly agree" to "strongly disagree." We used survey participants' responses in the Importance-Satisfaction (I-S) analysis to identify which attributes passengers found most important and which (based on their collective in-the-moment perceptions at a wide array of transit stops and stations) tended to need the most improvement. We then employed ordered logistic regression analyses to determine the relative importance of the five-category attributes to users' collective satisfaction with the transit facility at the time of their transfer. The survey also contained 12 questions about passenger demographics and trip characteristics, such as race/ethnicity, gender, household income, trip purpose, available mode alternatives, and station accessibility.

We carefully selected a dozen transit stops and stations in metropolitan Los Angeles to reflect the enormously wide variety of such facilities (Figure 1). Despite 
its image as perhaps the most sprawling, car-oriented American metropolis, Los Angeles is neither. To the surprise of many, Los Angeles is the nation's most densely populated urbanized area. It has fewer lane-miles of streets and roads per capita than all but Honolulu. In addition, while the residents of a dozen urbanized areas, on average, drive fewer miles per day than Angelinos, the residents of the remaining 452 urbanized areas drive more (U.S. Federal Highway Administration 2008). Overall transit use (measured in terms of unlinked trips) in Los Angeles ranks second nationally to New York, while transit use per capita ranks 10thbehind New York, San Francisco-Oakland, Washington, Boston, Chicago, Philadelphia, Portland, Baltimore, and Seattle. ${ }^{3}$ The stops and stations selected ranged from a simple bus stop signpost on a crowded, dirty street corner to the striking Union Station/ Gateway Center complex with its six modes of transit service and mission-style leather chairs in the waiting areas. Our aim was to survey a wide array of transit users at a wide array of transit stops and stations to reflect, as much as possible, the diverse experiences of transit users generally. ${ }^{4}$

We then classified the stops and stations into five categories, from simple local bus stops to major intermodal transfer facilities, based on quantitative and qualitative evaluations of the 1) volume of passengers and activities, 2) number of interfacing routes, 3) number of interfacing modes, 4) physical configuration, 5) extent and quality of amenities, 6) transit center scope (community, regional, or other), and 7) presence of commercial joint developments (Fruin 1985).

Passengers were surveyed at different times of the day on different days of the week between December 2006 and March 2007. We approached 1,023 passengers, and a total of 749 riders participated ( $73 \%$ response rate). Most declinations occurred because the person was leaving the stop or station or because the bus or train was due shortly. In addition, it should be noted that not all of the 749 surveys were fully completed, as many survey participants had to stop taking the survey in order to catch their bus or train. 


\section{Intermodal Transfer Facilities}

Surveyed transfer facilities in Los Angeles County
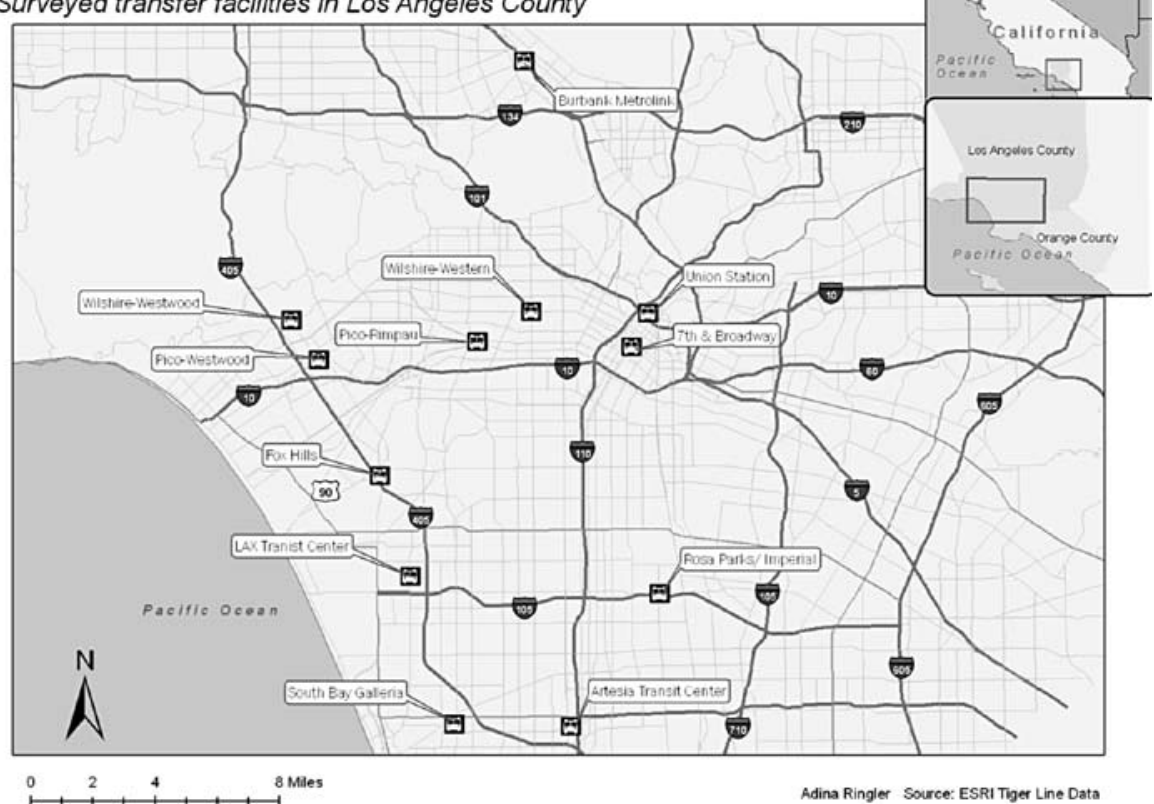

Adina Ringler Source: ESRI Tiger Line Data

\begin{tabular}{|c|c|c|}
\hline Station Name & Station Type & Level \\
\hline L.A. Union Station & $\begin{array}{c}\text { Bus-Heavy Rail- } \\
\text { Light Rail- } \\
\text { Commuter Rail }\end{array}$ & $\begin{array}{l}\text { 5: A major grade-separated, multi-modal, } \\
\text { multi-level bus or rail-transfer facility. }\end{array}$ \\
\hline $\begin{array}{l}\text { Wilshire/Western (Purple HRT x } \\
\text { Metro Rapid) }\end{array}$ & Bus-Heavy Rail & \multirow{2}{*}{$\begin{array}{l}\text { 4: An urban grade-separated multi-modal } \\
\text { transit facility with exclusive bus access } \\
\text { provisions and elevated or subway rail } \\
\text { access. }\end{array}$} \\
\hline Imperial/Wilmington (Blue $x$ Green LRT) & Bus-Light Rail & \\
\hline Galleria at South Bay Transit Center & Bus & \multirow{6}{*}{$\begin{array}{l}\text { 3: An off-street facility, serving multiple } \\
\text { routes, and possibly multiple modes }\end{array}$} \\
\hline LAX Bus Center & Bus & \\
\hline Fox Hills Transit Center & Bus & \\
\hline Pico/Rimpau Transit Center & Bus & \\
\hline Artesia Transportation Center & Bus & \\
\hline Burbank Metrolink Station & Bus-Commuter Rail & \\
\hline Pico \& Westwood & Bus & \multirow{3}{*}{$\begin{array}{l}\text { 1: A local stop serving a single transit } \\
\text { mode }\end{array}$} \\
\hline Wilshire \& Westwood & Bus & \\
\hline Broadway \& 7 th (Metro Center) & Bus & \\
\hline
\end{tabular}

Note: Level 2 is a slightly upgraded form of facility-for example, an on-street bus turnout with loading bays separated from regular traffic lanes and raised platform rail station.

\section{Figure 1. Location of surveyed transit stops and stations in Los Angeles County}




\section{Analysis of Survey Data}

In the sections following, we present findings from the I-S analysis and ordered logistic regression analysis of transit users' perceptions of transit services and facilities, measuring attributes on the basis of both user satisfaction and importance to users. We confirmed that transit users' demographics and trip characteristics in our survey were comparable to those reported by the Los Angeles County Metropolitan Transportation Authority in 2002 (LACMTA 2002); the only exceptions were that the household incomes and the proportion of white riders were higher among our respondents. This is almost certainly because our surveys included more riders of suburban and commuter services operated by transit systems other than the central-city focused LACMTA.

\section{Importance-Satisfaction Analysis}

I-S analysis can help transportation planners and managers evaluate the relative priority they should place on various options (Tennessee Department of Transportation Office of Strategic Planning 2006). I-S analysis helps transit managers maximize the impact of new investments on customer satisfaction by focusing improvements in areas where customer satisfaction is low and importance to customers is high (Tennessee Department of Transportation Office of Strategic Planning 2006). Thus, using indices of improvement need (I-S rankings), transit agencies can direct investments toward improvements that will be most beneficial to their customers.

To obtain an attribute's importance rating, we calculated the proportion of respondents who ranked it "very important" out of the total number of valid answers in the survey. To obtain the satisfaction rating, we calculated the proportion of survey respondents who indicated satisfaction with the attribute ("strongly agree" or "agree somewhat"). These ratings are expressed in percentages. Based on the ratings of 16 attributes (excluding riders' reported overall satisfaction level), we determined rankings for both importance and satisfaction.

Then, the I-S rating was computed for each attribute by multiplying the importance rating by 1 minus the satisfaction rating.

$$
\begin{aligned}
\text { IS } \quad & =[\text { Importance } \times(1 \text {-Satisfaction })] \\
& =\quad[\text { Importance } \times \text { Dissatisfaction }]
\end{aligned}
$$

The maximum rating of 1.00 occurred when all respondents considered an attribute "very important," but no respondents were satisfied with the current quality 
of the attribute. The minimum rating of 0.00 occurred when one of the following was true:

1. No respondents considered the attribute "very important," and/or

2. All respondents were at least somewhat satisfied with the current quality of the attribute (i.e., all respondents chose "strongly agree" or "agree somewhat" with a satisfaction statement in the survey).

The I-S rating is thus an index that assesses the need for improvement; the higher the I-S rating, the greater the improvement need. Ideally, an agency could prioritize stop/station improvement planning based on I-S ratings, though in this study the results are aggregated across a dozen facilities to produce more general and generalizable levels of importance and satisfaction with the transfer experience at a heterogeneous set of surveyed transit facilities. If these data and I-S ratings were used for planning purposes, the data reported here would need to be disaggregated by facility.

\section{Rating and Ranking of Importance, Satisfaction Level, and Importance-Satisfaction}

After calculating I-S ratings for each of the attributes across the dozen facilities surveyed, we ranked each attribute from 1 st to 16 th. Table 1 shows 1 ) the proportion of respondents who placed the highest level of importance on each factor in the survey ("Rate") and rankings ("Rank") from 1st to 16th for each of the criteria (with a rank of "1" indicating greatest important and highest satisfaction), 2) the proportion of respondents who placed the highest and second highest levels of satisfaction ("strongly agree" or "agree somewhat") on each issue, and 3) the I-S rating, which combines 1 ) and 2) in the "I-S" columns (codes in Table 1 are used in Figure 1). To enable comparisons across general attribute categories, the unweighted means of importance ratings, satisfaction ratings, and I-S ratings and rankings for each category are also shown in the shaded rows in Table 1.

Table 1 shows that "safety at night" received the highest importance ranking (78\%), followed closely by the "safety during the day" (77\%). This indicates that, overall, passengers felt that safety and security are the most important factors in determining their stop/station experience. The third most important stop/station attribute (though very nearly equal to the first two safety factors) was schedule adherence (76\%), which in this analysis was categorized under Connection \& Reliability. So, while two safety and security (SS1 \& SS2) questions were ranked by 


\section{Table 1. Rating and Ranking for Importance, Satisfaction, and Importance-Satisfaction}

\begin{tabular}{|c|c|c|c|c|c|c|c|c|}
\hline \multirow{2}{*}{ Question on the Survey } & \multirow{2}{*}{$\begin{array}{l}\text { Cate- } \\
\text { gory }\end{array}$} & \multirow{2}{*}{ Code } & \multicolumn{2}{|c|}{ Importance } & \multicolumn{2}{|c|}{ Satisfaction } & \multicolumn{2}{|c|}{ IS } \\
\hline & & & Rate & Rank & Rate & Rank & Rate & Rank \\
\hline This station/stop area is clean. & \multirow{6}{*}{ 苑 } & A1 & $58 \%$ & 13 & $78 \%$ & 6 & $13.1 \%$ & 13 \\
\hline There are enough places to sit. & & $\mathrm{A} 2$ & $50 \%$ & 15 & $65 \%$ & 12 & $17.5 \%$ & 9 \\
\hline $\begin{array}{l}\text { There are places for me to buy } \\
\text { food or drinks nearby. }\end{array}$ & & $\mathrm{A} 3$ & $34 \%$ & 16 & $57 \%$ & 14 & $14.8 \%$ & 10 \\
\hline $\begin{array}{l}\text { There is a public restroom } \\
\text { nearby. }\end{array}$ & & A4 & $59 \%$ & 12 & $40 \%$ & 16 & $35.5 \%$ & 1 \\
\hline $\begin{array}{l}\text { There is shelter here to protect } \\
\text { me from the sun or rain. }\end{array}$ & & A5 & $69 \%$ & 8 & $69 \%$ & 8 & $21.2 \%$ & 7 \\
\hline Average & & $\mathrm{A}$ & $\underline{\underline{54.1 \%}}$ & $\underline{12.8}$ & $\underline{61.7 \%}$ & $\underline{11.2}$ & $\underline{\underline{20.4 \%}}$ & $\underline{\underline{8.2}}$ \\
\hline The signs here are helpful. & \multirow{3}{*}{ 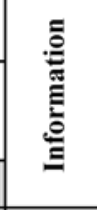 } & I1 & $69 \%$ & 9 & $81 \%$ & 4 & $13.3 \%$ & 12 \\
\hline $\begin{array}{l}\text { It is easy to get schedule and } \\
\text { route information at this } \\
\text { station. }\end{array}$ & & I2 & $62 \%$ & 11 & $66 \%$ & 11 & $21.4 \%$ & 6 \\
\hline Average & & I & $\underline{65.6 \%}$ & $\underline{10.0}$ & $\underline{73.2 \%}$ & $\underline{7.5}$ & $\underline{17.3 \%}$ & $\underline{9.0}$ \\
\hline $\begin{array}{l}\text { I usually have a short wait to } \\
\text { catch my bus/train. }\end{array}$ & \multirow{3}{*}{ 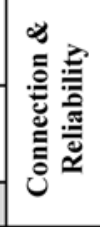 } & CR1 & $70 \%$ & 6 & $66 \%$ & 9 & $23.7 \%$ & 5 \\
\hline $\begin{array}{l}\text { My bus/train is usually on } \\
\text { time. }\end{array}$ & & CR2 & $76 \%$ & 3 & $67 \%$ & 10 & $25.0 \%$ & 4 \\
\hline Average & & $\mathrm{CR}$ & $\underline{72.8 \%}$ & $\underline{4.5}$ & $\underline{66.6 \%}$ & $\underline{9.5}$ & $\underline{24.3 \%}$ & $\underline{4.5}$ \\
\hline $\begin{array}{l}\text { It is easy to get around this } \\
\text { station/stop. }\end{array}$ & \multirow{3}{*}{ 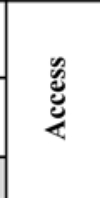 } & $\mathrm{ACl}$ & $57 \%$ & 14 & $89 \%$ & 1 & $6.2 \%$ & 16 \\
\hline $\begin{array}{l}\text { It's easy to find my stop or } \\
\text { platform. }\end{array}$ & & $\mathrm{AC} 2$ & $70 \%$ & 7 & $89 \%$ & 2 & $7.6 \%$ & 15 \\
\hline Average & & $\mathrm{AC}$ & $\underline{63.6 \%}$ & $\underline{10.5}$ & $\underline{89.1 \%}$ & $\underline{1.5}$ & $\underline{6.9 \%}$ & $\underline{15.5}$ \\
\hline I feel safe here during the day. & \multirow{6}{*}{ 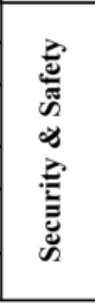 } & SS1 & $77 \%$ & 2 & $85 \%$ & 3 & $11.3 \%$ & 14 \\
\hline I feel safe here at night. & & SS2 & $78 \%$ & 1 & $57 \%$ & 13 & $33.1 \%$ & 3 \\
\hline $\begin{array}{l}\text { There is a way for me to get } \\
\text { help in an emergency. }\end{array}$ & & SS3 & $74 \%$ & 4 & $55 \%$ & 15 & $33.7 \%$ & 2 \\
\hline This station is well lit at night. & & SS4 & $73 \%$ & 5 & $74 \%$ & 7 & $18.9 \%$ & 8 \\
\hline $\begin{array}{l}\text { Having security guards here } \\
\text { makes me feel safer. }\end{array}$ & & SS5 & $67 \%$ & 10 & $79 \%$ & 5 & $13.9 \%$ & 11 \\
\hline Average & & SS & $\underline{73.8 \%}$ & $\underline{4.4}$ & $\underline{70.1 \%}$ & $\underline{8.6}$ & $\underline{20.4 \%}$ & $\underline{7.4}$ \\
\hline $\begin{array}{l}\text { This is an easy place to } \\
\text { transfer to another bus or } \\
\text { train. }\end{array}$ & $\begin{array}{l}\text { Over } \\
\text {-all }\end{array}$ & - & $73.1 \%$ & - & $88.3 \%$ & - & $8.6 \%$ & - \\
\hline
\end{tabular}

Note: A low Importance Rank value indicates that users deem an attribute highly important. A low Satisfaction Rank value indicates that users highly satisfied with an attribute. Low IS-ratings represent the greatest need for improvement. 
respondents as most important, the two questions on Connection \& Reliability (CR1 \& CR2) ranked just below Safety, also rated as relatively important by users.

The "satisfaction" columns in Table 1 show the ratings and rankings for riders' satisfaction with each attribute at the heterogeneous set of stops and stations where surveys were conducted. Most respondents (88\%) are at least somewhat satisfied with the overall quality stops where they were surveyed. Among the five categories examined, Access received the highest average satisfaction rating (89\%). Respondents also were generally satisfied with the ease of navigating to, from, and within the facilities. Within the Information category, signs received a very high satisfaction rating $(81 \%)$, while riders rated availability of schedule and route information lower (66\%). The Connection \& Reliability category received a low average rating overall, indicating that passengers were relatively dissatisfied with schedule adherence and wait times.

Table 1 shows that individual stop/station attribute ratings varied significantly within the Amenities and Security \& Safety categories. In the Security \& Safety category, in particular, there was a large gap in the level of satisfaction between daytime and nighttime safety. Most respondents were satisfied with the level of safety during the day (85\%), but 43 percent did not feel safe at night.

Based on the I-S rating, the availability of a public restroom (35.5\%), an emergency contact method (33.7\%), and safety at night (33.1\%) were, in the views of respondents, the three things most in need of improvements across all of the transit stops and stations surveyed. The high $\mathrm{I}-\mathrm{S}$ ranking for restrooms indicates that passengers felt strongly that more (and better) ${ }^{5}$ public restrooms should be provided at transit stops and stations. For those who were transferring at their stop or station, an emergency communication device (such as a panic button at stops) and general safety at night were especially strong concerns.

Riders assigned high priority to two items in the Connection \& Reliability category: schedule adherence (25\%) and wait time (23.7\%). The reliability of transit service is very important to riders, yet, other than personal experience, most riders have no access to either real-time or historical information about a particular line's schedule adherence-though this is slowly changing with growth of real-time "next bus/train" information at stops/stations. These results suggest that either providing such real-time information or improving published schedule adherence could substantially reduce the perceived burdens of transit travel. 
Figure 2 shows the importance ratings on the $X$-axis and the satisfaction ratings on the $\mathrm{Y}$-axis (the letter/digit codes in this figure relate to those presented in the 3rd column of Table 1). This figure visually summarizes the relationship between the relative importance and level of satisfaction these 749 transit users attribute to each service feature at the dozen stops and stations surveyed. By plotting the importance and satisfaction ratings of each attribute relative to the means, transfer facility attributes can be classified into four categories.

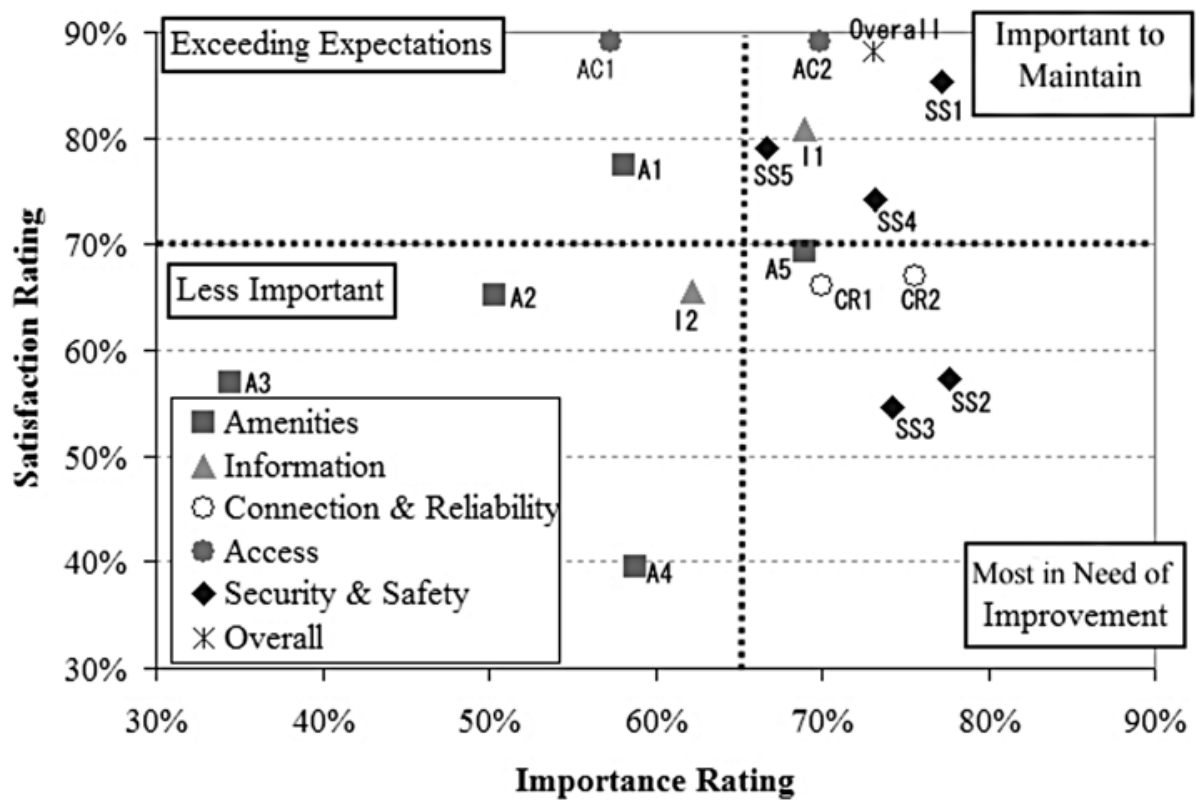

Figure 2. Four categories of importance and satisfaction levels

Attributes that fall in the bottom-right quadrant ("Most in Need of Improvement") require immediate attention due to low average satisfaction combined with high average importance ratings. These attributes include availability of emergency communication devices (SS3), overall safety at night (SS2), availability of public restrooms (A5), schedule adherence (CR1), and average wait time (CR2).

The top-right quadrant of Figure 2, labeled "Important to Maintain" depicts attributes that surveyed users have rated "very important" and with which they are relatively satisfied. Such responses suggest that entities overseeing these stops and stations are doing a relatively good job on factors that are very important to users. The attributes in this category fall under Safety \& Security, Access, and Informa- 
tion and include station lighting (SS4), presence of security guards (SS5), general safety during the day (SS1), ease of accessing schedule and route information (I1), and ease of locating the stop or platform (AC2).

Two attributes received very high satisfaction ratings, but below-average importance ratings (labeled "Exceeding Expectations" in the top-left quadrant). In the Access category, passengers were most satisfied with the ease of navigating around the station or stop (AC1) and, in the Amenities category, passengers were satisfied with the cleanliness of the facility (A1). These results suggest that the surveyed transit facilities are meeting users' expectations for these attributes.

The last group of attributes ("Less Important" in the bottom-left box) received low user satisfaction and importance ratings. These attributes were (somewhat surprisingly to us) seating (A2), places to buy food or drink (A3), shelter from the rain or sun (A4, perhaps reflecting the mild Southern California climate), and the helpfulness of the signs at the station/stop (12).

The I-S ratings by category suggest that Connection \& Reliability at the dozen Los Angeles transit stops and stations surveyed require the most improvement relative to the four other categories. We can thus expect that improvement of on-time performance and implementation of timed transfers would likely significantly affect user satisfaction. Although Safety \& Security received the highest importance ranking, it received a moderate satisfaction rating for the stops and stations surveyed, which yielded the second highest I-S rating. Safety \& Security was the most important factor in determining whether travelers choose to use transit, and it can increase perceived costs related to waiting infinitely; that is, if travelers feel a waiting/transfer location is profoundly unsafe, most will forego using public transit entirely (ITE Technical Council Committee 5C-1A 1992). In this sense, respondents in this survey, who are already traveling by transit, may exhibit a higher Safety \& Security satisfaction level than the general population.

\section{Relative Importance of Transfer Facility Attributes based on Satisfaction Ratings}

One of the central questions motivating this research is which transit stop and station attributes most influence traveler's decisions to use public transit. The more satisfied transit users are with their waiting, walking, and transferring experiences, the more likely they are to take transit. In order to examine relative importance of transit stop and station attributes, we conducted chi-square tests and ordered logistic regression analyses, using the various satisfaction ratings described above. ${ }^{6}$ 
In our survey, the dependent variable had four ordinal categories: strongly agree, agree, disagree, and strongly disagree.

We then employed chi-square tests to confirm that all of the responses to the 16 questions about individual stop/station attributes do indeed influence the distribution of responses to the question about users' overall satisfaction with the stop or station. As expected, we found that responses to each of the questions about individual attributes did influence the users' overall satisfaction with the stop/station where the survey was conducted in a statistically significant sense.

Because chi-square tests do not indicate the ordered effect of each of the attribute responses on overall stop/station satisfaction levels, we performed a series of simple ordered logistic regression analyses relating each of the 16 independent variables from the survey to the overall satisfaction question. Since each of the explanatory variables are ordinal, we used three dummy (or dichotomous $[0,1]$ ) variables to differentiate among the four levels of responses. Pseudo- $R^{2}$, which is similar to $\mathrm{R}^{2}$ in Ordinary Least Regression (OLS), is an indicator of the goodness of fit; it was used to examine the relative performance of each factor in explaining passengers' overall satisfaction with a stop or station. The pseudo- $\mathrm{R}^{2} \mathrm{~s}$ of the single ordered logistic regression analyses collectively show that overall ease of navigation at the transfer center, personal safety, and service reliability are the most important contributors to a passenger's overall satisfaction with a stop or station. Specifically:

1. "It's easy to get around this station/stop" (pseudo- $\mathrm{R}^{2}=0.16$, significant at 3 response levels) ${ }^{7}$ is most important overall.

2. "I usually have a short wait to catch my bus/train" (pseudo- $\mathrm{R}^{2}=0.12$, significant at 3 response levels) is second.

3. "It's easy to find my stop or platform" (pseudo- $R^{2}=0.12$, significant at 1 response level) is third.

4. "This station is well lit at night" (pseudo- $\mathrm{R}^{2}=0.11$, significant at 2 response levels) is fourth.

5. "Having security guards here makes me feel safer" (pseudo- $R^{2}=0.10$, significant at 1 response level) is fifth.

In contrast, station amenities and cleanliness (public restrooms, food/drink sales, places to sit, shelter from sun/rain, and cleanliness) were least important in explaining respondents' overall satisfaction. ${ }^{8}$ 
In addition to the single ordered logistic regression analysis, we conducted a multivariate ordered logistic regression analysis to examine the simultaneous effects of the 16 independent user perception variables on reported overall levels of stop/station satisfaction for 512 valid observations. After numerous iterations in which we sought to identify a set of statistically significant independent variables while taking into account the sometimes high levels of collinearity among them, we obtained the results shown in Table 2, which presents our final model. The independent variables in this model are listed in order of the scale of their effects (coefficients). The pseudo $\mathrm{R}^{2}$ in this model indicates that approximately 27 percent of the variance in the level of user stop/station satisfaction is explained by the variance of the seven independent variables included in the final model. The first and second columns show the level of response (3-agree and 4-strongly agree as opposed to the two other responses, disagree and strongly disagree, combined as the base) and a stop/station attribute. For example, "CR2-4" and "My bus/train is usually on time" indicate that a dummy variable was used to measure users' "strong agreement" with the satisfaction of on-time performance. The columns labeled " $\mathrm{z}$ " and " $\mathrm{P}>|\mathrm{z}|$ " indicate that all variables included in this parsimonious final model are statistically significant at the $95 \%$ confidence level.

Since all variables in the model are dichotomous dummy variables used to indicate whether the users' overall stop/station satisfaction level is something other than "strongly disagree," we can compare coefficients among variables directly. However, as this is not a linear regression model, the effects of coefficients reported in Table 2 to determine the overall satisfaction level are not linear as in the OLS. Instead, the effects should be interpreted as the probability that a given factor will effect a change in each overall satisfaction level (Table 3).

The penultimate row in Table 2 shows the cut point (or threshold value) separating those who disagree or strongly disagree with a statement that they are satisfied overall with the transit stop or station (in other words, that they are unsatisfied or very unsatisfied with the stop or station overall), and those who agree with the statement that they are satisfied with the stop or station. Likewise, the last row shows the cut point between those who are satisfied with the stop or station, and those who are very satisfied. ${ }^{9}$ It should be noted that we obtained similar results from the statements "I feel safe here at night" (SS2) and "I feel safe here during the day" (SS1). Due to the high correlation between these two variables, however, we included just one (SS1: "I feel safe here during the day") of these two variables in the final model. 
Journal of Public Transportation, Vol. 13, No. 3, 2010

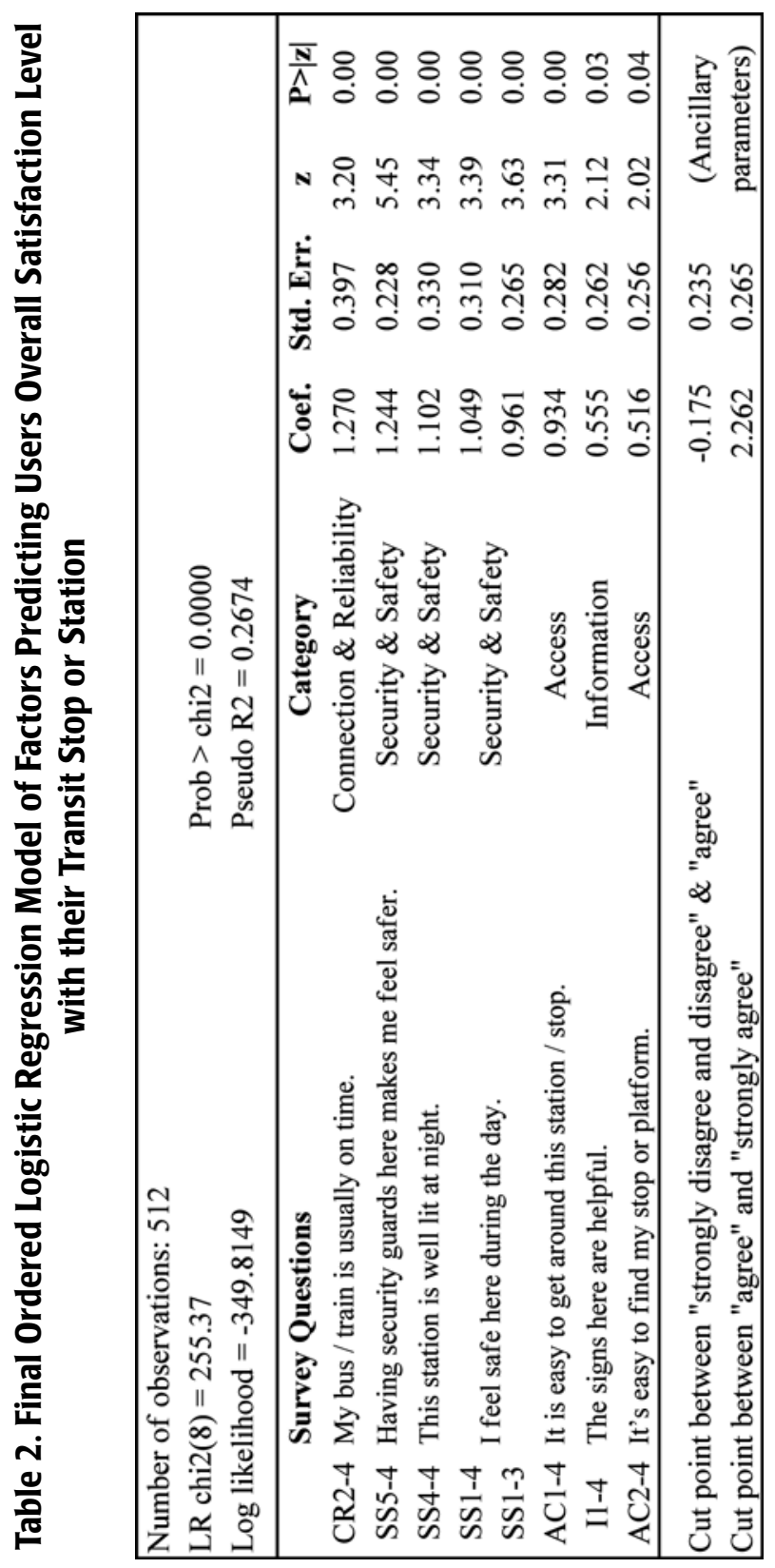




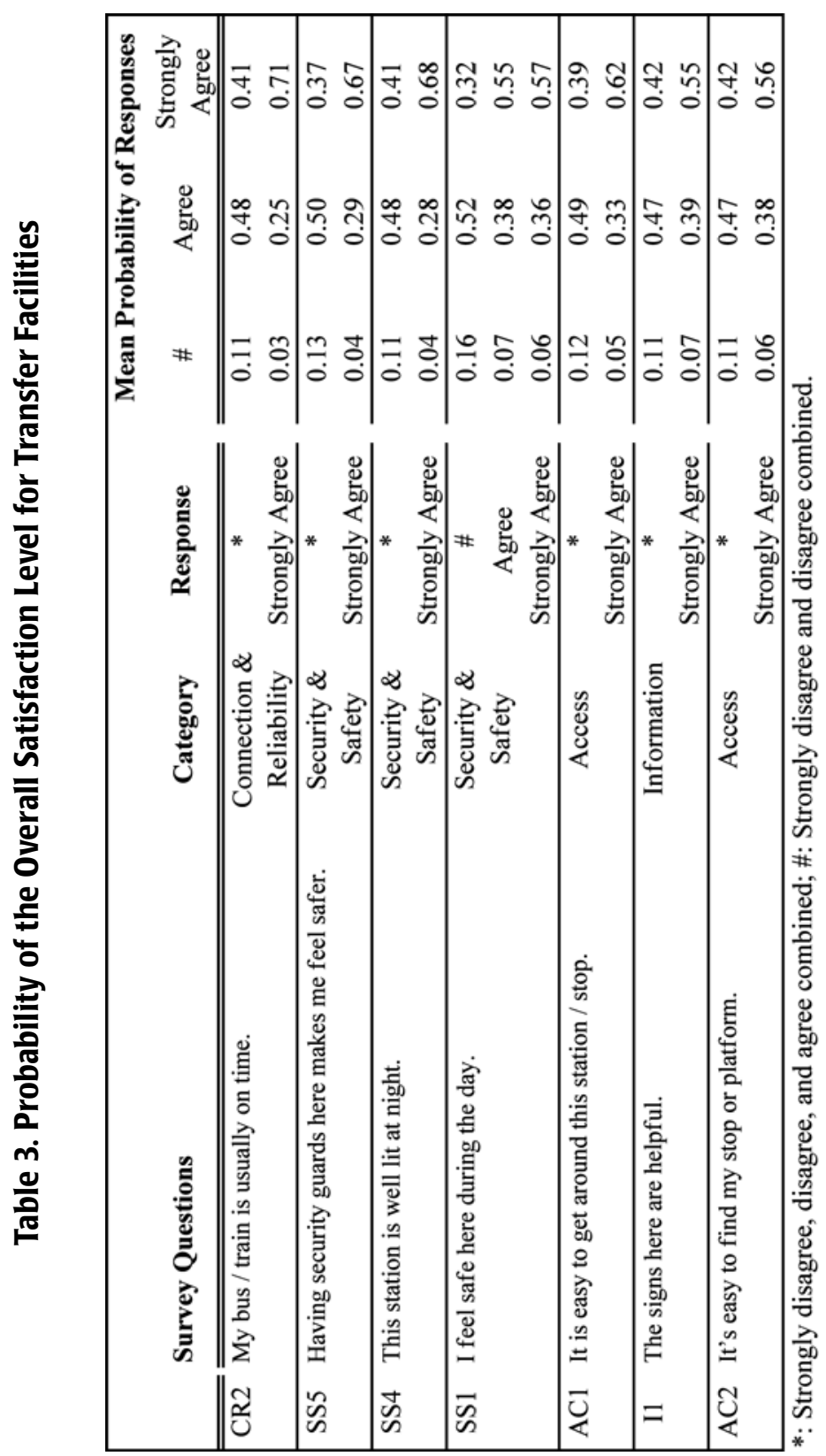


This multivariate ordered logistic regression analysis considers the influence of each of many stop or station attributes while controlling, to the extent possible, for the independent influence of other attributes. Thus, the scale of coefficients in Table 2 indicates the relative importance of the explanatory variables examined. Significantly, the most important factor in determining respondents' overall satisfaction with a transit stop or station has nothing to do with the stop or station itself-it is the on-time performance of the transit service. This is an important finding, though it should come as no surprise to anyone familiar with travel behavior research. Put another way, the perceived burden of waiting for or transferring between transit vehicles is reduced substantially by reliable and frequent service. This finding is all the more reliable because the respondents to this survey were aware that the foci of our analysis were transit stops and stations, and not transit service in general.

Following schedule adherence, the next three most important stop or station attributes, according to those surveyed for this study, concern personal safety (security guards, lighting, and overall perceptions of security). The three factors after that related to the navigability of the stop or station (easy to get around, signs are helpful, easy to find stop or platform).

To see how a response to the quality of each attribute influences the overall satisfaction level for the facility, probabilities of a given overall stop/station satisfaction level were calculated from the estimated coefficients in Table 2 using the mean values for all variables in the regression model. Table 3 shows that the satisfaction level with each of the final model's attributes clearly influences the users' overall satisfaction level with the transit stop or station. For example, when a transit user is strongly satisfied with on-time performance (CR2), the probability that this person is strongly satisfied with the overall quality of the transit facility increases from 0.41 to 0.71 . This same interpretation applies to all of the variables listed.

Overall, the results of this ordered logistic regression are consistent with our findings from the I-S analysis. Connection and reliability factors are the most important, followed by security and safety factors. A few attributes in the Access and Information categories also significantly influence users' satisfaction levels, but amenities in general are not nearly as important as the other attributes tested. 


\section{Concluding Remarks}

In this article, we sought to address the general lack of causal clarity that plagues much previous research on transit stops and stations. We examined 749 transit users' perceptions of the quality of service and built environment at 12 transit stops and stations around metropolitan Los Angeles, employing an Importance-Satisfaction analysis, chi-square tests, and ordered logistic regression analyses to examine which stop and station attributes matter most to transit users' experience.

The principal finding of this analysis is clear: the most important determinant of user satisfaction with his/her transit stop or station had little to do with physical characteristics of that stop or station-it is frequent, reliable service in an environment of personal safety. While this study was confined to 749 transit users surveyed at all times of the day and week at 12 very different transit stops in one very large metropolitan area, we believe that both the size and heterogeneity of the sample permit us to generalize somewhat from these findings. To wit, most transit users would prefer short, predictable waits for buses and trains in a safe, if simple or even dreary, environment, over long waits for late-running vehicles in even the most elaborate and attractive transit facility, especially if they fear for their safety. While this finding will come as no surprise to those familiar with past research on the perceptions of transit users, it does present a rather dramatic contrast to much of the descriptive, design-focused research on transit transfer facilities (Rabinowitz et al. 1989; Project for Public Spaces 1999; Texas Transportation Institute, Texas A\&M Research Foundation, and Texas A\&M University 1996), and to public transit finance policies and programs that strongly emphasize capital expenditures over operating.

Of our 16 stop and station attributes evaluated, transit users assigned the highest importance to factors related to security and safety, and then to factors related to connection and reliability. In contrast, stop and station-area amenities were ranked as least important by users. Respondents' level of satisfaction with each attribute under the current conditions at the 12 survey sites in the Los Angeles metropolitan area indicates that users are least happy with factors related to access, followed by some factors related to security and safety and connection and reliability. The I-S rating, which combines users' perception of the importance of and satisfaction with various aspects of the waits/walk/transfer experience at individual transit facilities, indicates that factors most in need of improvement tend to pertain to security and safety and connection and reliability and least to amenities. This is not to say that physical amenities are not important to travelers 
-more than half ranked information, public restroom availability, cleanliness, and ease of navigation as important. Rather, travelers prefer safe, frequent, reliable service over such factors.

We also employed the ordered logistic regression model to measure the influence of each of the 16 stop/station attributes on users' overall satisfaction with their wait/walk/transfer experience at each transit facility, while simultaneously controlling for the effects of all other measured "satisfaction" attributes. This type of analysis tends to eliminate all but one of closely-related factors (such as "I feel safe here at night" and "This stop/station is well-lit at night") while elevating ostensibly less-important factors that independently influence users' overall levels of satisfaction. This analysis indicates that the most important factor affecting transit users' overall stop/station satisfaction is on-time performance, followed by presence of a security guard for safety, adequate lighting, adequate safety during the day, ease of getting around a facility, and good signage.

These findings should be heartening to transit managers focused on delivering quality transit service to users. A relatively large body of research suggests that transit subsidy programs, particularly the federal programs, strongly favor capital expenditures on facilities and vehicles over operating expenditures on service (Pickrell 1986; Wachs 1989; Li and Taylor 1998; Taylor and Samples 2002). While the reasons behind this capital bias are many, they collectively encourage a focus on the physical characteristics of transit vehicles, stops, and stations over improvements to service frequency or reliability. While comfortable, informative, and attractive stops and stations can make traveling by public transit more agreeable, what passengers really want most - at least in this sample-is safe, frequent, and reliable service, plain and simple.

\section{Acknowledgements}

This research was funded by the California Department of Transportation (Caltrans), and the authors are grateful for this support. The accuracy of the data reported and the conclusions drawn are solely those of the authors, and not the funding agency. Three other researchers-Mark Miller (UC Berkeley PATH Program), Adina Ringler (UCLA Institute of Transportation Studies), and Michael Smart (UCLA Institute of Transportation Studies) - contributed significantly to the larger research project on which this article is based; this article would not have been possible without their efforts. Thanks also go to Kansai Uchida (UCLA 
Institute of Transportation Studies) for his editorial help with this article; Bruce Chapman (Division of Research and Innovation) who managed this project for Caltrans; UCLA student Ting Sit, who helped design and administer the survey and collate and analyze the data; UCLA students Syed-Abrar Ahmed, Lanka Ranasinghe, and Karla Vasquez, who helped administer the survey; and UCLA student Vanessa Fernandez, who translated the survey from English into Spanish. We would also like to thank the anonymous reviewers of this manuscript for their valuable comments and suggestions. Finally, thanks also go to LACMTA, Metrolink, Santa Monica Big Blue Bus, and Culver CityBus for allowing us to survey their passengers and to the 749 Los Angeles area transit riders who took the time to respond to the survey.

\section{Endnotes}

${ }^{1}$ We extensively review the literature on valuation of out-of-vehicle travel time -waiting time, walking time, transferring time, and non-time-specific transfer penalties-vis-à-vis in-vehicle time in (Iseki and Taylor 2009).

${ }^{2}$ Travel time uncertainty is likely perceived as a significant burden by most travelers. Atkins and Polak (1997) show that the relative weight values of mean and one-standard deviation of wait times are 2.6 and 2.5, respectively, which suggests that reducing arrival time uncertainty (or increase in waiting time reliability) has about the same effect on generalized costs of transit trip as a corresponding reduction in headways.

${ }^{3}$ Authors' calculations from U.S. Federal Highway Administration, 2006, Table HM-72, and American Public Transit Association at http://www.apta.com/ research/stats/ridership/uzapmiles.cfm.

${ }^{4} \mathrm{~A}$ detailed analysis of the responses to this survey is available from the authors.

${ }^{5} \mathrm{~A}$ relatively high share (43\%) of the stops and stations in this sample actually had a restroom available, while 57 percent of respondents were surveyed stops/stations with no public restrooms nearby - the latter characterizing the situation at most transit stops nationwide. While 71 percent of respondents at no-restroom stops/station were unsurprisingly very or somewhat dissatisfied with the availability of restrooms, 46 percent of respondents at with-restrooms stops were similarly dissatisfied. This speaks, perhaps, to the quality of the public restroom experience at transit stops and stations-that they tend to be better in theory than practice. 
${ }^{6}$ The chi-square test is a method used to examine whether the distribution of observations among categories of a dependent variable is influenced by another categorical variable (Fox 1997; StataCorp LP 2005). Ordered logistic regression is a method used to examine the relationships between a series of independent variables and an ordinal dependent variable. As in other logistic regression models, the dependent variable is not continuous, but categorical. In ordered logistic regression, the particular order of values in the dependent variable is important, while differences between two consecutive values of a dependent variable are not. More details on the use of ordered logistic regression model can be found in STATA manuals (2005) and other advanced statistics textbooks.

7 "Response level" refers to a user response of 1-strongly disagree, 2-disagree, 3-agree, and 4-strongly agree to a statement that the user is satisfied with each stop or station attribute.

${ }^{8}$ While our findings here regarding restrooms would appear to contradict our earlier findings from the IS analysis that transit users consider stop/station area restrooms important and are largely unsatisfied with them, the findings are in fact consistent.

${ }^{9}$ Cut point values are used to compute probabilities that each observation with certain independent variable values fall within each category of a dependent variable, taking into account the disturbance factor, which is assumed to be logistically distributed (StataCorp LP 2005). For example, when all independent values of the obtained regression model are zero, then probabilities for each of three categories $(1 \& 2,3$, and 4$)$ are $0.456,0.449$, and 0.094 , respectively.

\section{References}

Atkins, W. S., and J. Polak. 1997. Bus reliability-Stated preference research. London: For the Department of Transport.

Balcombe, R., R. Mackett, N. Paulley, J. Preston, J. Shires, H. Titheridge, M. Wardman, and P. White. 2004. The demand for public transport: A practical guide. TRL Report TRL593. London: TRL.

Barton-Ashman Associates, Inc. 1993. Estimation, calibration, and validation of the Houston mode choice model. Technical report. Prepared for Metropolitan Transit Authority of Harris County, Houston, TX. 
Bronzaft, A. L., S. B. Dobrow, and T. J. O'Hanlon. 1976. Spatial orientation in a subway system. Environment and Behavior 8(4): 575-594.

Bruzelius, N. 1979. The Value of Travel Time: Theory and Measurement. London: Croom Helm.

Committee on Intermodal Transfer Facilities, Transportation Research Board. 1974. Intermodal transfer facilities research needs. Transportation Research Record 505: 43-46.

Dziekan, K., and K. Kottenhoff. 2007. Dynamic at-stop real-time information displays for public transport: Effects on customers. Transportation Research Part A: Policy and Practice 41: 489-501.

Dziekan, K., B. Schlag, and I. Jünger. 2004. Barrieren der bahnnutzung - mobilitätshemmnisse und mobilitätsbedürfnisse. Verkehrspsychologie. Mobilität - Verkehrssicherheit - Fahrerassistenz, B. Schlag, Ed. Pabst Science Publisher, Lengerich.

Dziekan, K., and A. Vermeulen. 2006. Psychological effects of and design preferences for real-time information displays. Journal of Public Transportation 9(1): 71-89.

Dziekan, K. 2008. Ease-of-use in public transportation: A user perspective on information and orientation aspects. Doctoral thesis, Royal Institute of Technology, Stockholm, Sweden.

Evans, J. E. 2004. Chapter 9: Transit scheduling and frequency. TCRP Report 95: Traveler Response to Transportation System Changes. Washington D.C.: Transportation Research Board.

Fox, J. 1997. Applied Regression Analysis, Linear Models, and Related Methods. Thousand Oaks: Sage Publications.

Fruin, J. J. 1985. Passenger information systems for transit transfer facilities. Synthesis of Transit Practice 7, edited by N.C.T.R.D.P. (U.S.). Washington, D.C.: Transportation Research Board National Research Council.

Guo, Z., and N. H. M. Wilson. 2004. Assessment of the transfer penalty for transit trips: Geographic information system-based disaggregate modeling approach. Transportation Research Record 1872: 10-18.

Hess, D., J. Brown, and D. Shoup. 2005. Waiting for the bus. Journal of Public Transportation 7(4): 67-84. 
Iseki, H., and B. D. Taylor. 2009. Not all transfers are created equal: Toward a framework relating transfer connectivity to travel. Transport Reviews 29(6): 777-800.

ITE Technical Council Committee 5C-1A. 1992. The location and design of bus transfer facilities. ITE Journal: 33-37.

Kim, K. H. 1998. Technical specifications for the March 1998 travel demand model. Portland, OR: Metro Transportation Department.

Kittelson \& Associates, Inc., Texas Transport Institute, and Transport Consulting Limited. 2003. Transit Capacity and Quality of Service Manual - 2nd Edition. Washington, D.C.: National Academic Press.

Lacy, D., and P. Bonsall. 2001. Misperception and mode choice. World Conference on Transportation Research (WCTR), Seoul, South Korea.

Li, J., and B. D. Taylor. 1998. Outlay rates and the politics of capital versus operating subsidies in federal transit finance. Transportation Research Record 1618: 78-86.

Liu, R., R. M. Pendyala, and S. Polzin. 1997. Assessment of intermodal transfer penalties using stated preference data. Transportation Research Record 1607: 74-80.

Los Angeles County Metropolitan Transit Authority (LACMTA). 2002. On board bus survey weekday passenger report. Los Angeles, CA.

Moreau, A. 1992. Public transport waiting times as experienced by customers: Marketing research involving the Grenoble system. Public Transport International 41(3): 52-68.

MVA Consultancy, ITS University of Leeds, TSU University of Oxford. 1987. Value of travel time savings. Policy Journals, Newbury, Berks.

Parsons Brinckerhoff Quade and Douglas Inc. 1993. Calibration of the mode choice models for the Minneapolis-St. Paul Region. Prepared for the Metropolitan Council.

Parsons Brinckerhoff Quade and Douglas Inc. 1998. Cleveland regional travel demand forecasting model documentation report. Prepared for the Greater Cleveland Regional Transit Authority and the Northeast Ohio Areawide Coordinating Agency. 
Parsons Brinckerhoff Quade and Douglas Inc. 1999. Travel demand model development methodology report. North Illinois Regional Commuter Railroad Corporation (METRA).

Pickrell, D. 1986. Federal operating assistance for urban mass transit: Assessing a decade of experience. Transportation Research Record 1078: 1-10.

Project for Public Spaces, Inc., with Multisystems, Inc.. 1999. The role of transit amenities and vehicle characteristics in building transit ridership: Amenities for transit handbook and the transit design game workbook. Transit Cooperative Research Program, Washington, D.C., National Academy Press.

Rabinowitz, H. Z., E. A. Beimborn, P. S. Lindquist, and D. M. Opper. 1989. Market based transit facility design. U.S. Department of Transportation, Washington, D.C., Urban Mass Transportation Administration.

Reed, T. B. 1995. Reduction in the burden of waiting for public transit due to realtime schedule information: A conjoint analysis study. Paper presented at the Vehicle Navigation and Information Systems Conference, Seattle, WA.

Reynolds, M. M., and C. D. Hixson. 1992. Transit vehicle meets system: A method for measuring transfer times between transit routes. Transportation Research Record 1349: 35-41.

Ryan, A. 1996. The value of time. Research Note M(96)01. London: London Transport Marketing.

StataCorp LP. 2005. STATA Base Reference Manual. College Station, Texas: StataCorp LP.

Steer Davies Gleave. 1997. Transport quality and values of travel time. Prepared for TRENEN II STRAN: Trinity College Dublin.

Taylor, B. D., and K. Samples. 2002. Jobs, jobs, jobs: Political perceptions, economic reality, and capital bias in U.S. transit subsidy policy. Public Works Management and Policy Journal 6(4): 250-263.

Tennessee Department of Transportation Office of Strategic Planning. 2006. 2006 TDOT Statewide Customer Satisfaction Survey.

Texas Transportation Institute, Texas A\&M Research Foundation, and Texas A\&M University. 1996. Guidelines for the location and design of bus stops. Transit Cooperative Research Program, Washington, D.C., National Academy Press. 
U.S. Environmental Protection Agency. 2000. COMMUTER Model Coefficients. Washington, D.C.

U.S. Federal Highway Administration. 2008. Highways statistics. Washington, DC: U.S. Department of Transportation. Tables HM-71 \& HM-72. Available at: http://www.fhwa.dot.gov/policyinformation/statistics/2008/.

Vuchic, V. R., and S. Kikuchi. 1974. Design of outlying rapid transit station areas. Transportation Research Record 505: 1-12.

Wachs, M. 1989. U.S. transit subsidy policy: In need of reform. Science $244: 1545-$ 1549.

Wardman, M. 2001. A review of British evidence on time and service quality valuations. Transportation Research Part E, Logistics and Transportation Review 37E(2-3): 107-128.

Wardman, M. J. Hine, and S. Stradling. 2001. Interchange and travel choice, volume 1. Scottish Executive Central Research Unit.

Webster, F. V., and P. H. Bly. 1980. The demand for public transport. Report of the International Collaborative Study of the Factors Affecting Public Transport Patronage. Crowthorne, Berkshire, England: TRL Limited.

Woyciechowicz, A., and R. Shliselberg. 2005. Wayfinding in public transportation. Transportation Research Record 1903: 35-42.

\section{About the Authors}

HIROYUKI ISEKI (hiseki@uno.edu) is Assistant Professor of Planning and Urban Studies School of Urban Planning and Regional Studies at the University of New Orleans.

BRIAN D. TAYLOR, AICP, (btaylor@ucla.edu) is Professor and Chair of Urban Planning and Director, UCLA Institute of Transportation Studies, at the University of California at Los Angeles. 